\title{
Dissecting the susceptibility/resistance mechanism of Vitis vinifera for the future control of downy mildew
}

\author{
Valentina Ricciardi ${ }^{1}$, Demetrio Marcianò ${ }^{1}$, Maryam Sargolzaei ${ }^{1}$, Elena Marrone Fassolo ${ }^{1}$, Daniela Fracassetti $^{2}$, Matteo \\ Brilli $^{3}$, Mirko Moser ${ }^{4}$, Vahid Shariati J. ${ }^{5}$, Elahe Tavakole ${ }^{6}$, Giuliana Maddalena ${ }^{1}$, Alessandro Passera ${ }^{1}$, Paola Casati $^{1}$, \\ Massimo Pindo ${ }^{4}$, Alessandro Cestaro ${ }^{4}$, Alex $\mathrm{Costa}^{3}$, Maria Cristina Bonza ${ }^{3}$, David Maghradze ${ }^{7,8}$, Antonio Tirelli ${ }^{1}$, \\ Osvaldo Failla ${ }^{1}$, Piero Attilio Bianco ${ }^{1}$, Fabio Quaglino $^{1}$, Silvia Laura Toffolatti ${ }^{*}$, and Gabriella De Lorenzis ${ }^{1 *}$ \\ ${ }^{1}$ Department of Agricultural and Environmental Sciences, Milan, Italy \\ ${ }^{2}$ Department of Food, Environmental and Nutritional Sciences, Milan, Italy \\ ${ }^{3}$ Department of Biosciences, Milan, Italy \\ ${ }^{4}$ Edmund Mach Foundation, Research and Innovation Centre, San Michele all'Adige, Trento, Italy \\ ${ }^{5}$ National Institute of Genetic Engineering and Biotechnology, Shahrak-e Pajoohesh, km 15, Tehran - Karaj Highway, Tehran, Iran \\ ${ }^{6}$ Department of Crop Production and Plant Breeding, College of Agriculture, Shiraz University, Shiraz, Iran \\ ${ }^{7}$ National Wine Agency of Georgia, Tbilisi, Georgia \\ ${ }^{8}$ Caucasus International University, Tbilisi, Georgia
}

\begin{abstract}
The Eurasian grapevine (Vitis vinifera), a species cultivated worldwide for high-quality wine production, is extremely susceptible to the agent of downy mildew, Plasmopara viticola. Nevertheless, germplasm from Georgia (Southern Caucasus, the first grapevine domestication centre), characterized by a high genetic variability, showed resistance traits to $P$. viticola. The cultivar Mgaloblishvili exhibited the most promising phenotype in terms of resistance against $P$. viticola. Its defence response results in: i) low disease intensity; ii) low sporulation; iii) damaged mycelium; iv) production of antimicrobial compounds such as volatile organic compounds (VOCs), whose effectiveness on the pathogen was evaluated by leafdisc assays. At the transcriptomic level, its resistance mechanism is determined by the differential expression of both resistance and susceptible genes. The resistance genes are related to: i) pathogen recognition through PAMP, DAMP and effector receptors; ii) ethylene signalling pathway; iii) synthesis of antimicrobial compounds (VOCs) and fungal wall degrading enzymes; iv) development of structural barriers (cell wall reinforcement). The first putative susceptible gene was the transcription factor VviLBDIf7 gene, whose validation was carried out by dsRNA (double-stranded RNA) assay. In this work, these unique results on plant-pathogen interaction are reviewed with the aim of developing new strategies to control the disease.
\end{abstract}

\section{Georgian germplasm, not only the first grapevine domestication centre}

Archaeological and palaeobotanical findings pointed out the Caucasus as the first grapevine (Vitis vinifera) domestication centre [1]. This evidence has been confirmed by genetic diversity studies. The genetic characterization of Georgian germplasm was performed by both SSR (simple sequence repeat) [2-4] and SNP (single nucleotide polymorphism) [5-7] molecular markers. Both molecular markers showed high levels of genetic diversity and heterozygosity, attesting the uniqueness and originality of this germplasm in comparison with the European and Central Asian germplasms [3,8-11]. Does this genetic diversity reflect a diversity at the phenotypic level? Do Georgian cultivars show resistance to pathogens, such as Plasmopara viticola?

$P$. viticola is the causal agent of grapevine downy mildew, one of the most important diseases at the international level. P. viticola, native of Northern America, was fortuitously introduced in France during the nineteenth century and rapidly spread across Europe [12]. The pathogen infects all green parts of the plant causing extensive losses in grape yield [13]. European $V$. vinifera cultivars are generally considered susceptible to $P$. viticola. Nevertheless, little information is available on the less common germplasm, such as the Georgian germplasm. Phenotypic investigations aimed to identify possible sources of resistance to $P$. viticola were carried out on Georgian cultivars. The estimation of resistance levels to $P$. viticola by both experimental inoculations and disease assessment in field conditions, allowed us to identify cultivars responding to infection with a lower disease intensity $[14,15]$. One of these is the cultivar called Mgaloblishvili. Mgaloblishvili is a local blackberry variety from Imereti province in the Western Georgia (Fig. 1). Mgaloblishvili showed a constant resistant behaviour, by reducing the disease severity and

\footnotetext{
*Corresponding author: gabriella.delorenzis@unimi.it; silvia.toffolatti@unimi.it
} 
the pathogen sporulation (Fig. 2), with susceptibility levels lower than $25 \%[14,16]$.

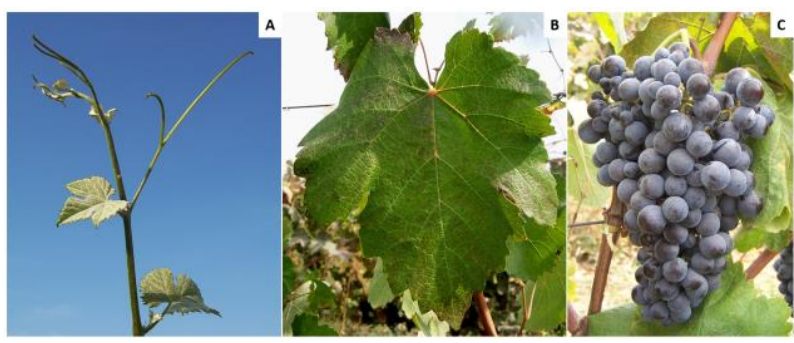

Fig. 1. Mgaloblishvili. A: tip. B: mature leave. C: bunch.
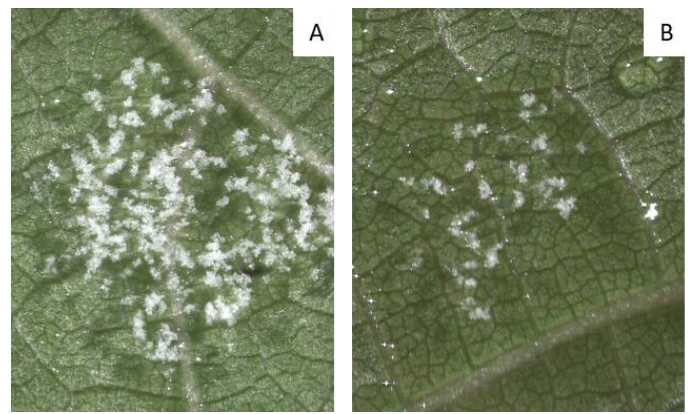

Fig. 2. $P$. viticola sporulation on the susceptible cultivar Pinot noir (A) and on the resistant cultivar Mgaloblishvili (B). A reduced sporulation density is visible on Mgaloblishvili.

\section{How does Mgaloblishvili counteract $P$. viticola?}

In Mgaloblishvili, confocal microscopy detected a normal colonization of leaf tissues by $P$. viticola up to 2 days after inoculation (dai), where the asexual spores of the pathogen penetrated through the stomatal pore differentiating the substomatal vesicle, the primary hypha and the first haustorium. At 3 dai, $P$. viticola mycelium showed evident alterations: hyphae were hyper-branched, contorted and ill defined. At 6 dai, dead portions of mycelium, surrounded by callose barriers were visible, as well as, short, hyperbranched and partly sterile sporangiophores emerging from the stomata [16].

At the transcriptomic levels, the resistance mechanism results in the overexpression of resistance genes involved in the plant defence pathway and related to: i) pathogen recognition through PAMP (pathogenassociated molecular patterns), DAMP (damageassociated molecular patterns) and effector receptors; ii) phytohormone signalling based on ethylene; iii) resistance response based on synthesis of antimicrobial compounds and fungal wall degrading enzymes; iv) cell wall reinforcement. For each step of plant defence pathway, putative resistance genes were identified. The rust resistance kinase $\operatorname{Lr} 10$ (a specific receptor able to recognize the effectors and ultimately to activate the defence mechanism) was involved in recognition, the ethylene-responsive transcription factor in signal transduction, and the endo-1,3;1,4- $\beta$-D-glucanase (a PR protein shown to be ethylene-responsive) and the valencene synthase (a sesquiterpene synthase) connected with the resistance response [16]. Future functional characterization studies will allow us to depict their role in the plant-pathogen interaction.

Besides grapevine genes, the genes overexpressed by the pathogen during the interaction with the plant were investigated. Multiple effector-encoding genes were identified in $P$. viticola transcriptome during the infection of Mgaloblishvili, with remarkable expression differences with the susceptible $V$. vinifera cultivar Pinot noir. Five apoplastic effector genes, putatively encoding for serine proteases involved in protein hydrolysis, specifically associated with resistance in Mgaloblishvili [17].

\section{The synthesis of VOCs to counteract the pathogen infection}

Volatile organic compounds (VOCs), such as terpenes, norisoprenoids, alcohols and aldehydes, are frequently emitted by plants in response to attack by pathogens [18]. This is also true for grapevine during $P$. viticola infection [16,19]. Transcriptional analysis revealed an overexpression of genes related to the biosynthesis of VOCs, such as valencene synthase and several cytochrome P450s, in Mgaloblishvili leaves inoculated with $P$. viticola [16]. Solid-phase microextraction gas chromatography-mass spectrometry analysis and the expression of terpene synthases ((E)- $\beta$-caryophyllene synthase, (E)- $\alpha$-bergamotene synthase, (E, E)- $\alpha$ farnesene synthase, (E)- $\beta$-ocimene synthase, $\alpha$-terpineol synthase and valencene synthase), revealed the biosynthesis of VOC in Mgaloblishvili leaves inoculated with $P$. viticola. After pathogen inoculation, the expression pattern of six terpene synthases increased rapidly (at 1 dai) and a constant increment of nine VOCs was observed from 1 dai to 3 dai, supporting the role of VOCs into defence mechanism of Mgaloblishvili against $P$. viticola. Interesting, four (farnesene, nerolidol, ocimene and valencene) out of nine VOCs caused a significant reduction $(53-100 \%)$ in $P$. viticola sporulation in leaf-disc assays, suggesting their potential role as a natural and eco-friendly solution for a sustainable protection of grapevine from $P$. viticola [20].

\section{New Rpv loci for the resistance to $P$. viticola}

So far, the investigation of the genetic basis of $P$. viticola resistance has led to the identification of 28 resistance loci in different regions of grapevine genome. These loci (designated $R p v=\underline{\text { Resistance }} \underline{P}$. viticola), identified through QTL (Quantitative Trait Loci) analysis on a range of North American and Asian Vitis (non-vinifera) species, confer different degrees of disease resistance, ranging from partial to total resistance [21].

Recently, three new loci (Rpv29, Rpv30 and Rpv31) associated with resistance to $P$. viticola have been identified in the vinifera germplasm coming from the Caucasus, using a GWA (Genome Wide Association) approach (Fig. 3). These new loci have been associated with a low level of pathogen sporulation [22]. Rpv29 
locus, located on chromosome 14, was mapped in the coding region of HEAT repeat-containing 5B protein, which is a required plant immunity protein. The other characterized genes in the surrounding regions are a probable cellulose synthase A catalytic subunit 8 [UDPforming], a acyl-CoA-binding domain-containing protein 3-like, a probable carboxylesterase 17 and a plant cadmium resistance 4 protein, which are genes involved in stress signaling and PAMP resistance [22]. The Rpv30 locus, located on chromosome 3, was in close distance to a MADS-box protein JOINTLESS-like, an ubiquitin carboxyl-terminal hydrolase 21, two magnesiumdependent phosphatases (MDP-1 and MDP-1-like), proteins with plant defensive role [22]. The Rpv31 locus was annotated in the linkage group of several rust resistance kinase Lr10-like genes on chromosome 16, associated with the $P$. viticola resistance trait in Mgaloblishvili [16]. Loci associated with the resistant traits are very useful in the breeding programs assisted by molecular markers [23]. Genes associated with the Rpv29, Rpv30 and Rpv31 loci are potential target genes for breeding of $P$. viticola resistant grapevine cultivars.

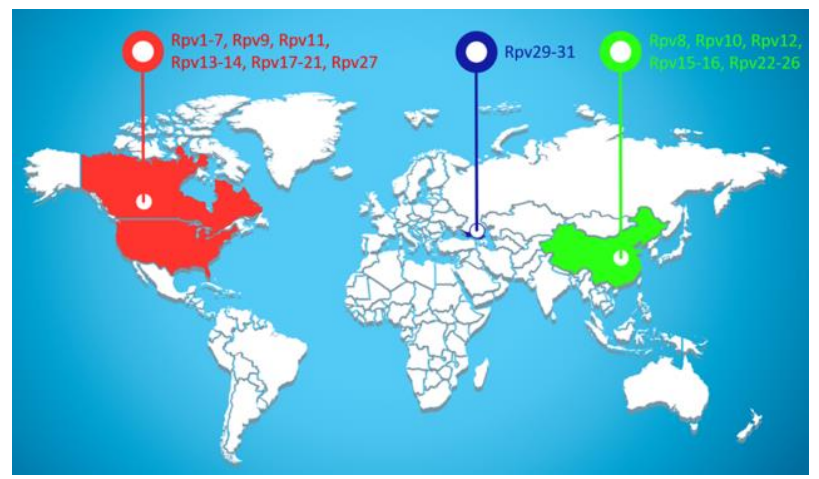

Fig. 3. Map of the origin of Rpv (Resistance $\underline{P}$. viticola) loci. In red, loci identified in North American Vitis species. In blu: loci identified in Georgian germplasm ( $V$. vinifera). In green: loci identified in Asian Vitis species.

\section{Besides resistance genes: the first putative susceptible gene}

Unfortunately, the resistance mechanisms based on single R (resistance) genes can be overcome due to the high adaptability of the pathogens. Indeed, $P$. viticola isolates that specifically overcome $R p v 3$, the major resistance gene carried by Bianca at chromosome 18 , have been already detected [24,25]. A point mutation in a gene encoding for a protein or effector may be enough to escape recognition [26]. To solve this inconvenience, resistance genes pyramiding has to be performed. A different strategy to obtain resistant cultivars can be achieved by exploiting S (susceptibility) genes [26]. Susceptibility genes are genes that facilitate the compatibility between plant and pathogen and are essential for their interaction, especially in the case of biotrophic pathogens, such as $P$. viticola. Mutation or loss of an $\mathrm{S}$ gene can limit the ability of the pathogen to cause disease.
Up to now, the only S genes known for grapevine are the MLO genes, whose knockdown confers resistance to the powdery mildew agent, reducing the disease severity up to $77 \%$ [27]. Recently, a candidate $\mathrm{S}$ gene for $P$. viticola resistance has been suggested. This gene, named VviLBDIf7, was found to be overexpressed in the susceptible cultivar Pinot noir 24 hours after the inoculation with $P$. viticola, while its expression was found to be decreased in the resistant Mgaloblishvili cultivar [17]. Moreover, its orthologous in Arabidopsis thaliana has been proven to confer resistance to Fusarium oxysporum when knockout [28]. VviLBDIf7 gene is a transcription factor belonging to a family of LOB (LATERAL ORGAN BOUNDARIES) transcription factor, which are involved in the regulation of plant organ development and in the response to abiotic and biotic stresses [29]. The inactivation of $V$ viLBDIf7 in $V$. vinifera could give proof of its involvement in $P$. viticola resistance.

RNA interference (RNAi) by exogenous doublestranded RNA (dsRNA) is a transient way to knockdown target genes [30]. This strategy has been used to knockdown the VviLBDIf7 gene in a highly susceptible grapevine cultivar (Pinot noir) to control $P$. viticola infections. Exogenous application of dsRNA led to significant reductions in both VviLBDIf7 gene expression and disease severity. In addition, clear alterations to both vegetative (hyphae and haustoria) and reproductive structures (sporangiophores) have been identified on leaves treated with dsRNA, resulting in a stunted growth and reduced sporulation [31]. These observations prove that VviLBDIf7 gene is a candidate gene to be silenced to reduce susceptibility to $P$. viticola.

\section{Conclusions}

The damages caused by $P$. viticola, combined with the ineffectiveness of agronomic practices in containing its diffusion, oblige frequent application of fungicides, making viticulture as the agricultural activity using the most intensive amount of plant protection products. The repeated use of fungicides impacts negatively on farm budgets and on human health and environment, and leads to the selection of resistance to fungicides. Moreover, the Directive 2009/128/EC and Regulation (EC) No. 1107/2009 of the European Parliament and of the Council concerning the placing and use of plant protection products on the market imposes to the farmers to reduce the use of agrochemicals during the next years. For these reasons, the cultivation of pathogen-resistant grapevine varieties is one of the most immediate strategies to reduce the impact of plant protection and ensure, at the same time, quantity and quality of yield.

If a few years ago resistance to $P$. viticola in $V$. vinifera was a utopia, today it is a certainty. Indeed, several Georgian cultivars showing resistance traits to $P$. viticola were identified and their study allowed us to identify putative resistance and susceptibility genes. These genes pave the way for the future of breeding programs, that can be based on innovative breeding technologies, such as the genome editing, or on MAS 
(Marker Assisted Selection), once the inheritance of the trait has been assessed. Finally, the identification of terpenes able to reduce downy mildew severity, as well as the ability of dsRNA to reduce pathogen infection, can be exploited for the development of new ecofriendly solutions to protect grapevine from $P$. viticola attack.

The research was supported by University of Milan, DiSAA, Research Support Plan 2015-2017, Linea 2 A, by the National Wine Agency of Georgia within the 'Research project for the Study of the Georgian Grapes and Wine Culture', and by European Union within the project titled "FREECLIMB - Fruit Crops Adaptation To Climate Change In The Mediterranean Basin" in the frame of the Programme Partnership For Research And Innovation In The Mediterranean Area (PRIMA; call 2018).

\section{References}

1. H. P. Olmo, P. E. McGovern, S. J. Fleming, and S. H. Katz, McGovern P, Éd. Orig. Anc. Hist. Wine. Amsterdam Gordon Breach 31, 43 (1995)

2. V. Laucou, T. Lacombe, F. Dechesne, R. Siret, J.-P. Bruno, M. Dessup, T. Dessup, P. Ortigosa, P. Parra, C. Roux, S. Santoni, D. Varès, J.-P. Péros, J.-M. Boursiquot, and P. This, Theor. Appl. Genet. 122, 1233 (2011)

3. S. Imazio, D. Maghradze, G. Lorenzis, R. Bacilieri, V. Laucou, P. This, A. Scienza, and O. Failla, Tree Genet. Genomes 9, 641 (2013)

4. J. Ekhvaia, M. Gurushidze, F. R. Blattner, and M. Akhalkatsi, Genet. Resour. Crop Evol. 61, 1507 (2014)

5. G. De Lorenzis, R. Chipashvili, O. Failla, and D. Maghradze, BMC Plant Biol. 15, 154 (2015)

6. V. Laucou, A. Launay, R. Bacilieri, T. Lacombe, A.-F. Adam-Blondon, A. Bérard, A. Chauveau, M. T. de Andrés, L. Hausmann, J. Ibáñez, M.-C. Le Paslier, D. Maghradze, J. M. Martinez-Zapater, E. Maul, M. Ponnaiah, R. Töpfer, J.-P. Péros, and J.-M. Boursiquot, PLoS One 13, 1 (2018)

7. F. Mercati, G. De Lorenzis, A. Mauceri, M. Zerbo, L. Brancadoro, C. D’Onofrio, C. Morcia, M. G. Barbagallo, C. Bignami, M. Gardiman, L. de Palma, P. Ruffa, V. Novello, M. Crespan, and F. Sunseri, Front. Plant Sci. 12, (2021)

8. S. Myles, A. R. Boyko, C. L. Owens, P. J. Brown, F. Grassi, M. K. Aradhya, B. Prins, A. Reynolds, J.-M. Chia, D. Ware, C. D. Bustamante, and E. S. Buckler, Proc. Natl. Acad. Sci. U. S. A. 108, 3530 (2011)

9. R. Bacilieri, T. Lacombe, L. Le Cunff, M. Di Vecchi-Staraz, V. Laucou, B. Genna, J.-P. Péros, P. This, and J.-M. Boursiquot, BMC Plant Biol. 13, 25 (2013)

10. S. Riaz, G. De Lorenzis, D. Velasco, A. Koehmstedt, D. Maghradze, Z. Bobokashvili, M. Musayev, G. Zdunic, V. Laucou, M. Andrew Walker, O. Failla, J. E. Preece, M. Aradhya, and R. Arroyo-Garcia, BMC Plant Biol. 18, 137 (2018)
11. G. De Lorenzis, F. Mercati, C. Bergamini, M. F. Cardone, A. Lupini, A. Mauceri, A. R. Caputo, L. Abbate, M. G. Barbagallo, D. Antonacci, F. Sunseri, and L. Brancadoro, BMC Plant Biol. 19, 7 (2019)

12. M. C. Fontaine, F. Austerlitz, T. Giraud, F. Labbé, D. Papura, S. Richard-Cervera, and F. Delmotte, Mol. Ecol. 22, 2771 (2013)

13. Y. Yu, Y. Zhang, L. Yin, and J. Lu, Phytopathology 102, 1094 (2012)

14. S. L. Toffolatti, G. Maddalena, D. Salomoni, D. Maghradze, P. A. Bianco, and O. Failla, Vitis - J. Grapevine Res. 55, 121 (2016)

15. N. Bitsadze, M. Aznarashvili, A. Vercesi, R. Chipashvili, O. Failla, and D. Maghradze, Vitis - J. Grapevine Res. 54, 193 (2015)

16. S. L. Toffolatti, G. De Lorenzis, A. Costa, G. Maddalena, A. Passera, M. C. Bonza, M. Pindo, E. Stefani, A. Cestaro, P. Casati, O. Failla, P. A. Bianco, D. Maghradze, and F. Quaglino, Sci. Rep. 8, 12523 (2018)

17. S. L. Toffolatti, G. De Lorenzis, M. Brilli, M. Moser, V. Shariati, E. Tavakol, G. Maddalena, A. Passera, P. Casati, M. Pindo, A. Cestaro, D. Maghradze, O. Failla, P. A. Bianco, and F. Quaglino, Genes (Basel). 11, 261 (2020)

18. N. Dudareva, F. Negre, D. A. Nagegowda, and I. Orlova, CRC. Crit. Rev. Plant Sci. 25, 417 (2006)

19. V. Lazazzara, C. Bueschl, A. Parich, I. Pertot, R. Schuhmacher, and M. Perazzolli, Sci. Rep. 8, 1618 (2018)

20. V. Ricciardi, D. Marcianò, M. Sargolzaei, G. Maddalena, D. Maghradze, A. Tirelli, P. Casati, P. A. Bianco, O. Failla, D. Fracassetti, S. L. Toffolatti, and G. De Lorenzis, Plant Physiol. Biochem. 160, 294 (2021)

21. D. Merdinoglu, C. Schneider, E. Prado, S. Wiedemann-Merdinoglu, and P. Mestre, OENO One 52, 203 (2018)

22. M. Sargolzaei, G. Maddalena, N. Bitsadze, D. Maghradze, P. A. Bianco, O. Failla, S. L. Toffolatti, and G. De Lorenzis, Front. Plant Sci. 11, (2020)

23. R. Eibach and R. Töpfer, in Grapevine Breed. Programs Wine Ind., edited by A. Reynolds (Elsevier B.V., 2015), pp. 3-22

24. E. Peressotti, S. Wiedemann-Merdinoglu, F. Delmotte, D. Bellin, G. Di Gaspero, R. Testolin, D. Merdinoglu, and P. Mestre, BMC Plant Biol. 10, 147 (2010)

25. S. Toffolatti, G. Venturini, D. Maffi, and A. Vercesi, BMC Plant Biol. 12, 124 (2012)

26. C. C. N. Van Schie and F. L. W. Takken, Annu. Rev. Phytopathol. 52, 551 (2014)

27. S. Pessina, L. Lenzi, M. Perazzolli, M. Campa, L. Dalla Costa, S. Urso, G. Valè, F. Salamini, R. Velasco, and M. Malnoy, Hortic. Res. 3, 16016 (2016)

28. L. F. Thatcher, J. J. Powell, E. A. B. Aitken, K. 
Kazan, and J. M. Manners, Plant Physiol. 160, 407 (2012)

29. C. Xu, F. Luo, and F. Hochholdinger, Trends Plant Sci. 21, 159 (2016)

30. A. S. Dubrovina and K. V. Kiselev, Int. J. Mol. Sci. 20, 2282 (2019)

31. D. Marcianò, V. Ricciardi, A. Marone Fassolo, E Passera, P. Bianco, O. Failla, P. Casati, G.

Maddalena, G. De Lorenzis, and S. Toffolatti, Front. Plant Sci. (2021) 